\title{
Prevalence and Predisposing Factors of Compartment Syndrome among Patients with Lower Limb Fracture at Assiut University Hospital
}

\author{
Mervat Abd El-Fatah Ismael, Zienab Abd-El-lateef Muhammad, Sahar Ali Abd El-mohsen \& Yasser \\ Mohamed Farouk. \\ Instructor, Adult Nursing Department, Faculty of Nursing, Assiut University, Assiut, Egypt. \\ Professor, Adult Nursing Department, Faculty of Nursing, Assiut University, Assiut, Egypt. \\ Lecturer, Adult Nursing Department, Faculty of Nursing, Assiut University, Assiut, Egypt. \\ Lecturer, Orthopedic Surgery and Traumatology Department, Faculty of Medicine, Assiut University, Assiut, Egypt.
}

\begin{abstract}
Compartment syndrome is a painful condition that most often occurs following trauma. The aim of the study was to identify the prevalence and predisposing factors of compartment syndrome among traumatic patients at Assiut University Hospital. Subjects and Method: This study was carried out in trauma unit at Assiut University Hospital. The study sample consisted of all patients with lower limb fractures admitted to trauma unit within 6 months period. The following tools were utilized for data collection: first tool "Patient's interview questionnaire ", second tool "Patients' assessment for the presence of compartment syndrome", third tool "Patients' assessment of risk factors sheet. Results: incidence of compartment syndrome among traumatic patients at Assiut University Hospital over six months period was 15 patients out of 217 lower limb fractured patients 6.9\%. Regarding the predisposing factors, the highest percentage $(53.3 \%)$ was related to crushing injury. Conclusion: The incidence of acute lower extremity compartment syndrome at Assiut University Hospital was 6.9\%. High energy injuries such as road traffic accidents and fall from height as well as gun-shot injuries are the most predominant precursors for lower extremity compartment syndrome. Recommendations: Monitoring of intra compartmental pressure for patients having risk factor for developing compartment syndrome should be considered to allow for early detection and management.
\end{abstract}

\section{Keywords: Prevalence, Predisposing Factors \& Compartment Syndrome.}

\section{Introduction}

A trauma patient is someone who has suffered a serious or life threatening injury as a result of an event such as a car accident, gunshot wound or fall. Traumatic injuries may affect many parts of the body, including the brain, the extremities and internal organs. The severity of injuries can range from minor to life-threatening. Trauma obviously affects the patient physically, but it can have lasting effects on the patient and those close to the patient emotionally (Nirula et al., 2010).

A bone fracture is a medical condition in which there is a damage in the continuity of the bone. Some fractures can lead to serious complications including a condition known as compartment syndrome. If not treated, compartment syndrome can eventually require amputation of the affected limb (Marshall \& Browner, 2012).

The muscle groups of the human limbs are divided into sections or compartments formed by strong unyielding fascial membranes. Compartment syndrome occurs when increased pressure within a compartment compromises the circulation and function of the tissues within that space. Compartment syndrome may occur acutely often following trauma or as a chronic syndrome seen most often in athletes, that presents as insidious pain (Mar et al., 2009).

Acute compartment syndrome occurs when the tissue pressure within a closed muscle compartment exceeds the perfusion pressure and results in muscle and nerve ischemia. It typically occurs subsequent to a traumatic event, most commonly a fracture (Park et al., 2009).

Acute compartment syndrome (ACS) most often develops soon after significant trauma, particularly involving long bone fractures. However, ACS may also occur following minor trauma or from non traumatic causes. In brief, any condition that decreases the capacity of a compartment or increases the volume of fluid within a compartment raises intra compartmental pressure and places the patient at risk for developing compartment syndrome (Metcalfe et al., 2011).

An annual incidence of ACS in U.S. was 3.5 per 100,000 populations. Most cases were secondary to trauma and the majority of these were associated with fracture, the risk increases with comminuted fractures. Both traumatic and non-traumatic CS predominantly affected the lower limb (Patel \& Haddad, 2005). 
There are many factors that may increase risk for ACS including: broken bones, especially the long bones of the arms and legs, crushing injuries, penetrating injuries, such as a knife wound that punctures the skin and tissue underneath, badly bruised muscles, poisonous bites, such as a snake bite, severe burns, blocked blood flow, a cast or bandage that is too tight, a surgical procedure with a tourniquet that may stop blood flow, lying for too long in a position that restricts blood flow, people who have nerve damage or if a person is unconscious for a long time, drugs used to build up muscles (anabolic steroids) and anticoagulants (Oprel et al., 2010).

Nurse has a very important role in detecting early signs and symptoms of neurovascular compromise and preventing occurrence of compartment syndrome. Monitoring neurovascular status is essential in early recognition of neurovascular deterioration or compromise. Delays in recognising neurovascular compromise can lead to permanent deficits, loss of a limb and even death (Ali et al., 2014).

\section{Significance of the study}

At trauma department many patients with lower limb (LL) fracture suffering from compartment syndrome as a complication of fracture. Compartment syndrome may lead to pain, deformity, paralysis, permanent muscle contraction (Volkmann's contracture), or loss of limb. More severe complications include systemic infection (sepsis) and renal failure may also occur if not early diagnosed and promptly treated; so this was the first nursing study to handle this issue in a trial to discover the prevalence and predisposing factors of this problem.

\section{The Aim of the study}

The aim of this study was to identify the prevalence and predisposing factors of compartment syndrome among traumatic patients at Assiut University Hospital.

\section{Research question}

What is the prevalence of compartment syndrome and what are the predisposing factors of compartment syndrome?

\section{Subjects \& Method \\ Research design}

A descriptive research design was utilized to conduct the aim of the study.

\section{Setting of the study}

This study was conducted in the trauma unit at Assiut University Hospital.

\section{Subjects}

The study sample consisted of all patients with lower limb fractures admitted to the trauma unit within 6 months period from 20/10/2015 to 20/4/2016 (183 males and 34 females) age ranges between 18- 65 years and agreed to participate in the study.

\section{Exclusion criteria}

Comatose patients, chronic diseases as (chronic obstructive pulmonary diseases (COPD), diabetes mellitus, heart diseases) and vascular diseases.

\section{Study tools}

Three tools were used in this study and were developed by the researcher to collect the necessary data for this study after reviewing national and international literature under guidance of supervisors. Tool (I): Patient's interview questionnaire:

This tool was developed by researcher to assess the patients' condition, it consisted of two parts:-

Part (1): Socio-demographic data of the patient:

It was developed to assess the patients' socio demographic characteristics. It included age, sex, date of admission, date of discharge, residence, educational level and occupation.

Part (2): Physical and medical data of the patient: It was developed to identify the patients' health problems (recent and past): This part was divided into general and localized assessment as follows:-

General physical and medical data of the patient: It included vital signs, height, weight, surgical history (type and date), family history of, asthma, epilepsy, cancer and previous medical history of the patients as: hypertension, angina, stroke, high cholesterol, kidney disease, cancer, asthma, lung disease, surgery, depression, epilepsy, drug or alcohol addiction, HIV, hepatitis B or C.

Localized physical and medical data of the patient: It included date and mechanism of injury.

Tool (II): Patients' assessment for the presence of compartment syndrome:

This tool was developed by the researcher based on literature review to assess patients with lower limb fracture for the presence of compartment syndrome. It included date of onset, signs and symptoms (pain out of proportion to injury, paraesthesia, paralysis, poikilothermia, pulselessness, pallor, delayed skin turgor and capillary refill time) and plain x-ray for assessing associated fractures.

\section{Tool (III): Patients' assessment of risk factors sheet}

This tool was developed by the researcher based on national and international literature review to assess risk factors for compartment syndrome as if it is following a fracture, crushing injury, severely bruised muscle, cast or tight bandage, prolonged limb compression, certain drugs, obesity and underlying diseases. 


\section{Methods}

Methods of data collection

- An official letter was issued from the Dean of the Faculty of Nursing to the Head of Trauma unit soliciting the necessary approval to conduct the present research after explaining the aim and nature of the study to them to obtain their cooperation.

- Three tools were developed based on a review of national and international related literature in the various aspects of the problem using books, articles, periodicals, and magazines was done.

- Content validity was established by panel of 5 expertises from orthopaedic surgery and nursing staff and then the tools were designed in their final format and tested for reliability using internal consistency for all of the tools which was measured using cronbach`s test. The tools proved to reliable (0.73.0.71 and 0.81, respectively).

- A pilot study was carried out to test the feasibility and practicability of the study tools on $10 \%$ of sample (about 20 patients). It also provided an estimate of time needed to fill out the tools, and those patients were included in the main study as there was no modifications.

- Data were collected from trauma unit at Assiut University Hospital during the period from October 2015 to April 2016. Each patient was interviewed to fill the study tools and to assess risk factors of compartment syndrome after fully explaining the aim and nature of the study to them.

\section{Ethical considerations}

- Research proposal were approved from Ethical Committee in the Faculty of Nursing.

- There was no risk for study subject during application of the research.

- The study was followed common ethical principles in clinical research.

- Oral consent was obtained from patients or guidance that were participated in the study, after explaining the nature and purpose of the study.

- Confidentiality and anonymity was assured.

- Study subject had the right to refuse to participate and or withdraw from the study without any rational any time.

- Study subject privacy was considered during collection of data.

\section{Statistical design}

Data entry and data analysis were done using SPSS version 19 (Statistical Package for Social Science). Data were presented as number, percentage, mean, standard deviation. Chi-square test was used to compare between qualitative variables. Wilcoxon Signed Rank Test was done to compare quantitative variables regarding before and after the occurrence of compartment syndrome in case of non-parametric data. P-value considered statistically significant when $\mathrm{P}<0.05$. 


\section{Results}

Table (1): Distribution of the studied patients regarding sociodemographic characteristics.

\begin{tabular}{|c|c|c|}
\hline & N. (217) & $\%$ \\
\hline \multicolumn{3}{|l|}{ Age } \\
\hline$<30$ years & 94 & 43.3 \\
\hline $30-40$ years & 66 & 30.4 \\
\hline$>40$ years & 57 & 26.3 \\
\hline Mean \pm SD (Range) & \multicolumn{2}{|c|}{$34.07 \pm 12.73(18.0-65.0)$} \\
\hline \multicolumn{3}{|l|}{ Sex: } \\
\hline Male & 183 & 84.3 \\
\hline Female & 34 & 15.7 \\
\hline \multicolumn{3}{|l|}{ Hospital stay } \\
\hline$<1$ week & 56 & 25.8 \\
\hline $1-<2$ weeks & 57 & 26.3 \\
\hline $2-<3$ weeks & 32 & 14.7 \\
\hline 3 weeks or more & 72 & 33.2 \\
\hline \multicolumn{3}{|l|}{ Residence } \\
\hline Urban & 37 & 17.1 \\
\hline Rural & 180 & 82.9 \\
\hline \multicolumn{3}{|l|}{ Education } \\
\hline High education & 29 & 13.4 \\
\hline Secondary school & 84 & 38.7 \\
\hline Read and write & 30 & 13.8 \\
\hline Illiterate & 74 & 34.1 \\
\hline \multicolumn{3}{|l|}{ Occupation } \\
\hline Working & 147 & 67.7 \\
\hline Not working & 70 & 32.3 \\
\hline
\end{tabular}

Table (2): Distribution of patients who developed compartment syndrome regarding mechanism of injury.

\begin{tabular}{|l|c|c|}
\hline \multicolumn{1}{|c|}{ Mechanism of injury } & N. (15) & \% \\
\hline Motor bike accident & 5 & 33.3 \\
\hline Road traffic accident & 4 & 26.7 \\
\hline Fall from height & 2 & 13.3 \\
\hline Fire arm injury & 4 & 26.7 \\
\hline
\end{tabular}

Table (3): Distribution of the patients with compartment syndrome regarding signs and symptoms.

\begin{tabular}{|l|c|c|}
\hline & N. (15) & \% \\
\hline Pain out of proportion of injury & 15 & 100.0 \\
\hline Paresthesia & 15 & 100.0 \\
\hline Paralysis & 9 & 60.0 \\
\hline Poikilothermia & 15 & 100.0 \\
\hline Pulselessness & 6 & 40.0 \\
\hline Pallor & 15 & 100.0 \\
\hline Turgor: & \multicolumn{2}{|c|}{} \\
\hline Delayed & 12 & 80.0 \\
\hline Normal & 3 & 20.0 \\
\hline Capillary refill time & 15 & 100.0 \\
\hline Delayed & 0 & 0.0 \\
\hline Normal & \multicolumn{2}{|l|}{} \\
\hline
\end{tabular}


Table (4): Distribution of associated fractures among patients with compartment syndrome

\begin{tabular}{|l|c|c|}
\hline \multicolumn{1}{|c|}{ Associated fractures } & N. (15) & \% \\
\hline Ankle & 2 & 13.3 \\
\hline Tibia- Fibula \& Ankle & 4 & 26.7 \\
\hline Tibia- Fibula & 4 & 26.7 \\
\hline Tibial plateau & 5 & 33.3 \\
\hline
\end{tabular}

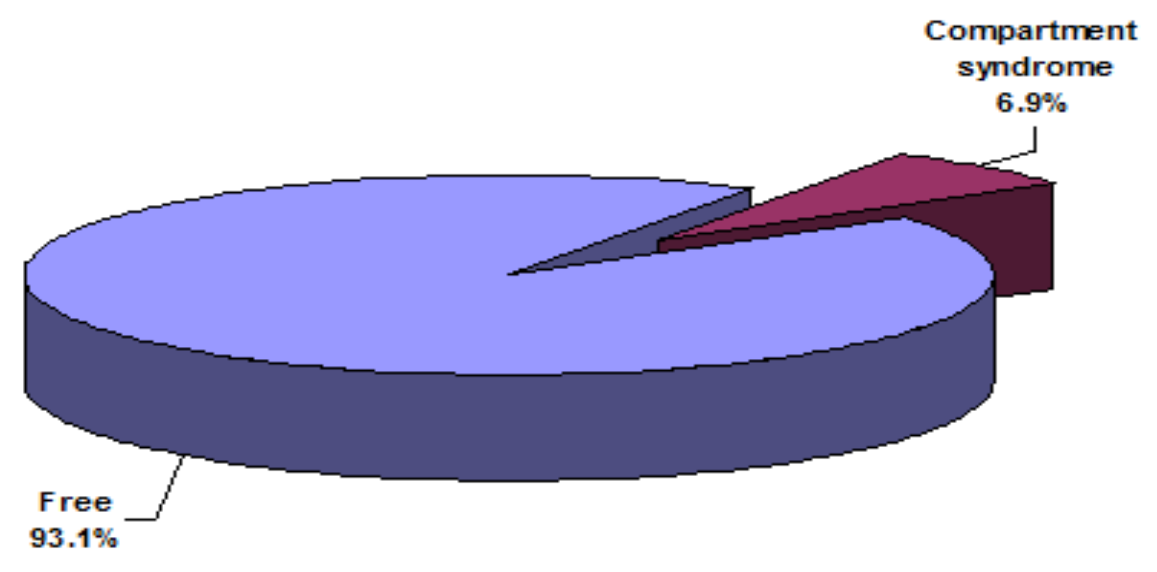

Fig.(1): Prevalence of compartment syndrome among patients with lower limb fractures.

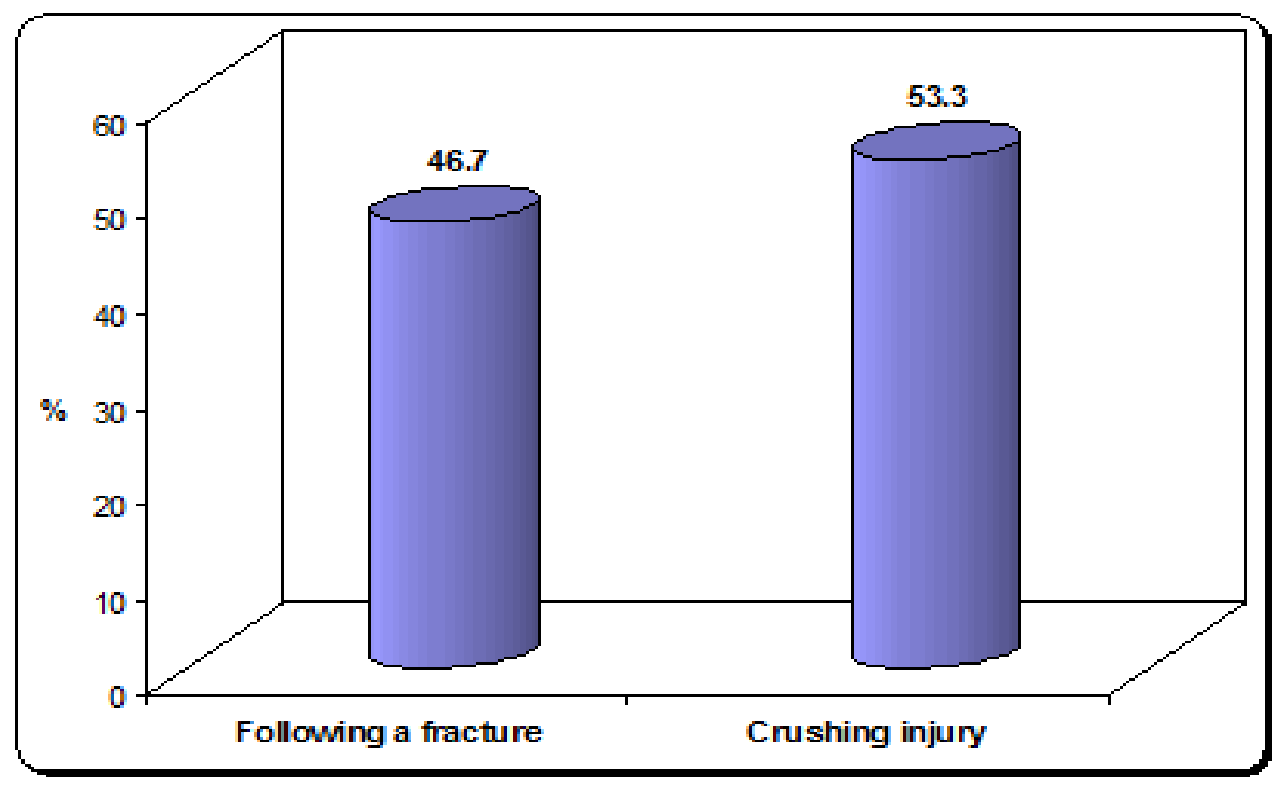

Fig.(2): Predisposing factors for development of compartment syndrome among patients with lower limb fractures.

Table (1): shows that the highest percent of the studied sample were male $(84.3 \%)$, their age less than 30 years $(43.3 \%)$, stayed in the hospital for 3 weeks or longer $(33.2 \%)$, living in rural areas $(82.9 \%)$, were having a secondary school education (38.7\%) and were working $(67.7 \%)$.

Table (2): shows that the highest percentage of the patients who developed CS regarding mechanism of 
injury was related to motor bike accident (33.3\%), followed by road traffic accident $\&$ fire arm injury with a percentage of $(26.7 \%)$ for both injures and fall from height $(13.3 \%)$.

Table (3): shows that regarding signs \& symptoms of compartment syndrome all patients who developed CS were having pain out of proportion of injury, Paresthesia , Poikilothermia , Pallor \& delayed capillary refill and $80 \%$ of them had delayed skin turgor, $60 \%$ had Paralysis of the affected limb and $40 \%$ had Pulselessness.

Table (4): shows that regarding the associated fracture in patients who developed C.S, the highest percentage was fracture of the tibial plateau (33.3\%) followed by tibia-fibula fracture and tibia-fibula $\&$ ankle with a percentage of $26.7 \%$ for both.

Figure (1): shows that $(6.9 \%)$ of the studied sample had developed a compartment syndrome

Figure (2): shows that regarding the risk factors for development of C.S, the highest percentage (53.3\%) was related to crushing injury, followed by following a fracture $(46.7 \%)$.

\section{Discussion}

The current study revealed that, more than half of the studied patients were males. This study finding was in line with a study conducted at trauma orthopaedic division, department of orthopaedics, university of British Columbia, Canada by (Babak et al., 2014) entitled as risk factors for acute compartment syndrome of the leg associated with tibial diaphyseal fractures in adults which revealed that; more than half of the study group were males.

The result of the present study revealed that, most of the studied patients their age less than thirty years $(43.3 \%)$ and $(30.4 \%)$ their age range from more than thirty and less than forty years. This result agree with (Jeffry et al., 2005) who carried out a prospective study for all cases of lower extremity compartment syndrome (LECS) over a 7 years period (2/1998$10 / 2005$ ) at trauma center in the United States entitled as Lower extremity compartment syndrome in the acute care surgery paradigm which revealed that the mean age of the studied patients was 33.3 years.

In the current study; it was found that the highest percentages in the studied patients were illiterate, workers and live in rural area. Regarding to hospital stay, it was found that the highest percentages in the studied patients stayed in hospital for more than 3 weeks.

The present study revealed that, high-energy injuries such as road traffic accident accounted for the majority of the initial causes of fracture especially involving motorbikes which was the common mean of transport for the studied patients in the community, followed by fire arm injury then fall from height, these results agreed with (Kuubiere et al., 2012) who found that in his study entitled as lower extremity compartment syndrome in northern Ghana: road traffic accident was the most common followed by fire arm injury and fall from height.

Regarding signs and symptoms of compartment syndrome the present study showed that pain out of proportion of injury and paresthesia was present in all of the studied patients followed by paralysis representing more than half of the sample. This result agreed with (Mithofer et al., 2004) who carried out a prospective study in department of orthopedic surgery, hospital for special surgery, New York, USA entitled as clinical spectrum of acute compartment syndrome of the thigh and its relation to associated injuries which revealed that pain with passive motion was present in all patients who were conscious, followed by paresthesia (60\%), and paralysis (42\%). Regarding associated fracture; the present study showed that nearly third of the sample were having tibial plateau fracture $(33.3 \%)$, more than fifth of the sample having tibia and fibula fracture $(26.7 \%)$, more than fifth of the sample having tibia, fibula $\&$ ankle $(26.7 \%)$ and more than tenth having ankle fracture (13.3\%). The tibia, due to its subcutaneous location and poor muscle coverage, is exposed and suffers large numbers of traumas, not only fractures, but also crush injuries and severe bruising, among others, which at any given moment, could lead to compartment syndrome in the patient. This result agreed with (Allmon et al., 2016) who found that in his study entitled as predictors of compartment syndrome occurring after tibial fracture: $12 \%$ for tibial plateau, $10 \%$ of the associated fracture was tibial fracture, $3 \%$ for tibial shaft, $2 \%$ for pilon fractures.

Incidence of compartment syndrome among traumatic patients at Assiut University Hospital over six months was 15 patients out of 217 lower limb fractured patients $(6.9 \%)$. This result agreed with (Park et al., 2009) who found that lower-leg acute compartment syndrome has been reported in $2 \%$ to $9 \%$ of tibial fractures.

According to this study, it was observed that nearly half of the studied patients had compartment syndrome following fracture and a little more than half of the studied patients had compartment syndrome following crushing injury this result disagreed with (McQueen et al., 2000) who carried out a study entitled as acute compartment syndrome. Who is at risk? In Scotland which revealed that in $69 \%$ there was an associated fracture and in $23 \%$ there was a crush injury. 


\section{Conclusions}

The present study concluded that; the incidence of acute lower extremity compartment syndrome at Assiut University Hospital was (6.9\%). High energy injuries such as those sustained from road traffic accidents and fall from height as well as Gun-shot injuries were the most predominant precursors for lower extremity compartment syndrome. There was a statistically significant difference (p-value 0,001) between the studied patients before and after occurrence of compartment syndrome regarding temperature and pulse, nearly third of the sample were having tibial plateau fracture, more than fifth of the sample having tibia and fibula fracture, more than fifth of the sample having tibia, fibula and ankle ,and more than tenth having ankle fracture, the present study showed that pain out of proportion of injury and paresthesia were present in all of the studied patients followed by paralysis representing more than half of the sample.

\section{Recommendations}

The study recommended that

- Monitoring of intra compartmental pressure in patients having risk factor for developing compartment syndrome as well as early referrals for orthopaedic specialist and trauma management should be considered to allow for early detection and management.

- Nurses must receive adequate knowledge on signs and symptoms of compartment syndrome for early detection and management.

\section{References}

1. Nirula R., Maier R., Moore E., Sperry J., \& Gentilello L., (2010): Scoop and run to the trauma center or stay and play at the local hospital: hospital transfer's effect on mortality. Journal of trauma. V. (69), N. (3), P.P (599-601).

2. Marshall S., \& Browner B., (2012): Emergency care of musculoskeletal injuries, 2nd ed, Ch: 20, P.P (480-520).

3. Mar G., Barrington M., \& Guirk B., (2009): Acute compartment syndrome of the lower limb and the effect of postoperative analgesia on diagnosis. British journal of anaesthesia. V. (102), N (1), P.P (3-11).

4. Park S., Ahn J., Gee A., Kuntz A., \& Esterhai J., (2009): Compartment syndrome in tibial fractures. Journal of orthopedic trauma.V.( 23), N (7), P.P(514-518).
5. Metcalfe D., Haider A., Olufajo O., Harri M., Zogg C., Rios Diaz A., Weaver M., \& Salim A., (2011): Access to post-discharge inpatient care after lower limb trauma. Journal of orthopedic research. V. (203), N. (1), P.P (140144).

6. Patel R., \& Haddad F., (2005): Compartment syndromes. British journal of hospital medicine.V.(66),N.(10), P.P(583-586).

7. Oprel P., Eversdijk M., Vlot J., Tuinebreijer W., \& Den hartog D., (2010): The acute compartment syndrome of the lower leg: a difficult diagnosis. Open orthopedic journal, V. (4), N. (1), P.P (115-119).

8. Babak Shadgan, Gavin Pereira, Matthew Menon, Siavash Jafari, Darlene Reid, \& Peter J., (2014): Risk factors for acute compartment syndrome of the leg associated with tibial diaphyseal fractures in adults. Journal of orthopedic traumatology. V. (16), N. (3), P.P (185-192).

9. Jeffry L., Kashuk, Ernest E., Moore, Sarah Pinski, Jeffrey L., Johnso, John B., Moore, Steven Morgan \& Clay C., Cothrenand Wade Smit (2005): Lower extremity compartment syndrome in the acute care surgery paradigm. Patient Safety in Surgery journal. V. (3), N. (1), P.P (11).

10. Kuubiere B., Callistus \& Abass Alhassan (2012): Lower extremity compartment syndrome in northern Ghana. Advances in applied science research. V. (5), N. (2), P.P (394-398).

11. Mithöfer K., Lhowe D., Vrahas M., Altman D., \& Altman G., (2004): Clinical spectrum of acute compartment syndrome of the thigh and its relation to associated injuries. Clinical orthopedic and related research. V. (425), N. (5), P.P (223-229).

12. Allmon C., Greenwell P., Paryavi E., Dubina A., \& O'Toole R., (2016): Radiographic predictors of compartment syndrome occurring after tibial fracture. Journal of orthopedic trauma. V. (27), N. (11), P.P (607-611).

13. Park S., Ahn J., Gee A., Kuntz A., \& Esterhai J., (2009): Compartment syndrome in tibial fractures. Journal of orthopedic traumatology. V. (23), N. (7), P.P ( 514-218).

14. McQueen M., Gaston P., \& Court-Brown C., (2000): Acute compartment syndrome. Who is at risk?. The journal of bone and joint surgery. V. ( 82), N. (2), P.P( 200-203).

15. Ali P., Santy-Tomlinson J., \& Watson R., (2014): Acute compartment syndrome of lower extremity. Orthopaedics and trauma journal. V. (23), N. (6), P.P (433-440). 